\title{
Pain after Discontinuation of Morphine Treatment Is Associated with Synaptic Increase of GluA4-Containing AMPAR in the Dorsal Horn of the Spinal Cord
}

\author{
David Cabañero', Alyssa Baker², Shengtai Zhou'², Gregory L Hargett', Takeshi Irie', Yan Xia', \\ Hélène Beaudry ${ }^{3}$, Louis Gendron ${ }^{3}$, Zara Melyan ${ }^{1,4}$, Susan M Carlton ${ }^{2,4}$ and Jose A Morón ${ }^{*, 1,4}$ \\ 'Department of Anesthesiology, College of Physicians and Surgeons, Columbia University, New York, NY, USA; ${ }^{2}$ Department of Neuroscience and \\ Cell Biology, University of Texas Medical Branch, Galveston, TX, USA; ${ }^{3}$ Département de Physiologie et Biophysique, Faculté de Médecine et des \\ Sciences de la Santé, Université de Sherbrooke, Sherbrooke, Quebec, Canada
}

\begin{abstract}
Withdrawal from prescribed opioids results in increased pain sensitivity, which prolongs the treatment. This pain sensitivity is attributed to neuroplastic changes that converge at the spinal cord dorsal horn. We have recently reported that repeated morphine administration triggers an insertion of GluA2-lacking ( $\mathrm{Ca}^{2+}$-permeable) $\alpha$-amino-3-hydroxy-5-methyl-4-isoxazole propionic acid receptors (AMPAR) in the hippocampus. This finding together with the reported involvement of AMPAR in the mechanisms underlying inflammatory pain led us to hypothesize a role for spinal AMPAR in opioid-induced pain behavior. Mice treated with escalating doses of morphine showed hypersensitivity to mechanical stimulation. Intrathecal administration of a $\mathrm{Ca}^{2+}$-permeable AMPAR selective blocker disrupted morphine-induced mechanical sensitivity. Analysis of the expression and phosphorylation levels of AMPAR subunits (GluAI/2/3/4) in homogenates and in postsynaptic density fractions from spinal cord dorsal horns showed an increase in GluA4 expression and phosphorylation in the postsynaptic density after morphine. Co-immunoprecipitation analyses suggested an increase in GluA4 homomers $\left(\mathrm{Ca}^{2+}\right.$-permeable AMPAR) and immunohistochemical staining localized the increase in GluA4 levels in laminae III-V. The excitatory postsynaptic currents (EPSCS) recorded in laminae III-V showed enhanced sensitivity to $\mathrm{Ca}^{2+}$-permeable AMPAR blockers in morphinetreated mice. Furthermore, current-voltage relationships of AMPAR-mediated EPSCs showed that rectification index (an indicator of $\mathrm{Ca}^{2+}$-permeable AMPAR contribution) is increased in morphine-treated but not in saline-treated mice. These effects could be reversed by infusion of GluA4 antibody through patch pipette. This is the first direct evidence for a role of GluA4-containing AMPAR in morphineinduced pain and highlights spinal GluA4-containing AMPAR as targets to prevent the morphine-induced pain sensitivity. Neuropsychopharmacology (20I3) 38, I472-1484; doi:I0.1038/npp.20 I3.46; published online 6 March 2013
\end{abstract}

Keywords: Morphine; pain; AMPAR; spinal cord; GluA4; synapse.

\section{INTRODUCTION}

Non-medical use of prescription opioids has dramatically increased during the last decade (http://www.unodc.org/ unodc/en/data-and-analysis/WDR-2011.html). Individuals who discontinue opioid use after repeated exposure develop an abstinence syndrome, in which one of the core symptoms is an increase in pain sensitivity. In patients treated with opioids, this hypersensitivity can increase the probability of abuse (Crofford, 2010). It is thought that the molecular mechanisms underlying opioid-induced hypersensitivity are regulated by plasticity events that converge

*Correspondence: Dr JA Morón, Department of Anesthesiology, Columbia University Medical Center, P\&S Box 46, 630 West 168th Street, New York, NY 10032, USA. Tel: + I 2123420023 , Fax: + I 212305 0777, E-mail: jm3473@columbia.edu

${ }^{4}$ These authors contributed equally.

Received 9 October 2012; revised I February 2013; accepted 7 February 2013; accepted article preview online 12 February 2013 at the dorsal horn of the spinal cord (Angst and Clark, 2006; Drdla et al, 2009).

$\alpha$-Amino-3-hydroxy-5-methyl-4-isoxazole propionic acid receptors (AMPAR) mediate fast excitatory transmission and have a critical role in synaptic plasticity in the spinal cord (Latremoliere and Woolf, 2009). AMPAR are tetramers consisting of dimers of four different subunits, GluA1-4, all of which are expressed in the dorsal horn (Polgar et al, 2008b). GluA2-containing AMPAR have low $\mathrm{Ca}^{2+}$ permeability, whereas GluA2-lacking AMPAR are readily permeable to $\mathrm{Ca}^{2+}$ (Malinow and Malenka, 2002).Trafficking of AMPAR is partially regulated by phosphorylation mechanisms. A phosphorylation of GluA1 or GluA4 subunits triggers receptor insertion into the synaptic membrane. On the contrary, a phosphorylation of GluA2 promotes removal of the receptor (Latremoliere and Woolf, 2009; Malinow and Malenka, 2002).

GluA2-lacking AMPAR in the spinal cord dorsal horn enhance neuronal excitability during persistent inflammatory pain (Kopach et al, 2011; Park et al, 2009). 
We have recently reported that following discontinuation of morphine treatment there is an increased insertion of GluA2-lacking ( $\mathrm{Ca}^{2+}$-permeable) AMPAR in the hippocampus (Billa et al, 2010; Xia et al, 2011).Therefore, we hypothesized a role for spinal cord $\mathrm{Ca}^{2+}$-permeable AMPAR in morphine-induced hypersensitivity. Here, we show that synaptic insertion of GluA4-containing $\left(\mathrm{Ca}^{2+}\right.$ permeable) AMPAR in the dorsal horn has a key role in morphine-induced pain hypersensitivity. In our experiments, mice exhibited mechanical hypersensitivity following discontinuation of morphine treatment. Intrathecal (i.t.) administration of a selective blocker of $\mathrm{Ca}^{2+}$-permeable AMPAR, 1-naphthylacetylsperimine (naspm), completely reversed this morphine-induced mechanical hypersensitivity. Additional biochemical analyses coupled with subcellular fractionation of spinal cord dorsal horns suggested that the increase in pain sensitivity was accompanied by synaptic insertion of GluA4-containing AMPAR. This increase in GluA4-containing AMPAR was localized in dorsal horn laminae III-V. In addition, whole-cell patchclamp recordings demonstrated that naspm reduced evoked excitatory postsynaptic currents (EPSCs) in the spinal cord slices of morphine-treated animals. To further confirm this finding, we studied current-voltage relationships of AMPAR-mediated EPSCs. We show that the rectification index (RI; an indicator of $\mathrm{Ca}^{2+}$-permeable AMPAR contribution) was increased in morphine-treated compared with salinetreated mice. Finally, we show that these effects of morphine on synaptic currents could be reversed by infusion of an anti-GluA4 antibody through patch pipette. Altogether, these data document a role for spinal GluA4-containing AMPAR in morphine-induced hypersensitivity and, therefore, identify spinal GluA4-containing AMPAR as a new target to disrupt morphine-induced pain.

\section{MATERIALS AND METHODS}

\section{Mice and Protocols}

C57BL-6 male mice of 3- to 8-week old were used. Protocols were approved by the respective Institutional Animal Care and Use Committees (Columbia University Medical Center, New York, NY, USA; The University of Texas Medical Branch, Galveston, TX, USA; Université de Sherbrooke, Sherbrooke, QC, Canada) and met the guidelines of the National Institutes of Health's (NIH) Guide for the Care and Use of Laboratory animals (Department of Health, Education, and Welfare publication no. 85-23, revised 1985, USA) and the International Association for the Study of Pain (Zimmermann, 1983).

\section{Morphine Treatment}

Mice received four escalating doses of morphine $(5,8,10$, and $15 \mathrm{mg} / \mathrm{kg}$, i.p.) or saline at $12 \mathrm{~h}$ intervals as previously described (Billa et al, 2010; Moron et al, 2007). Twelve hours after the last injection, mice were either evaluated in behavioral tests or killed for different analyses.

\section{Nociceptive Thresholds}

Sensitivity to mechanical and heat stimulation was always evaluated before 1500 hours. To minimize stress, mice were habituated to the environment for 3-4 days before testing and then evaluated before and $12 \mathrm{~h}$ after the treatment, except for the hot plate test.

\section{Von Frey Test}

Mechanical thresholds were evaluated by measuring the response to von Frey filament stimulation. Animals were placed in plastic boxes $(5 \times 5 \times 7.5 \mathrm{~cm})$ on a wire mesh grid, through which the filaments were applied (bending force ranged from 0.04 to $4 \mathrm{~g}$; Bioseb). Filament of $0.4 \mathrm{~g}$ was used first; thresholds were calculated using the up and down method as previously described (Chaplan et al, 1994). Clear paw withdrawal, shaking, or licking were considered nociceptive-like responses.

\section{Hot Tail-Flick test}

Mice were placed in cylindrical plexiglas tubes with their tails extending from the back of the tube. Tails were immersed in water at room temperature (RT) during habituation and in water at $46^{\circ} \mathrm{C}$ for evaluation of sensitivity to heat. The latency to flick the tail out of the water was recorded and the average values of four separate trials taken at $5 \mathrm{~min}$ intervals were obtained. The cutoff time was $30 \mathrm{~s}$.

\section{Hargreaves Test}

A modified Hargreaves test (Carlton et al, 2009) was used. Mice were placed in plastic boxes over a glass surface for $2 \mathrm{~h}$ before testing. The laser was then positioned under the plantar surface of the hind paw and parameters set to elicit latencies of $8-9 \mathrm{~s}$ in control mice (4.35 amp, $3.5 \mathrm{~W})$. The cutoff time was $15 \mathrm{~s}$ and mean withdrawal latencies were obtained from the average of three separate trials taken at 5-10 min intervals.

\section{Hot Plate Test}

Habituation was performed by placing the mice on the hot plate apparatus for $1 \mathrm{~min}$, with the plate at RT. On test day, the plate was set to $53{ }^{\circ} \mathrm{C}$. The testing end point was the latency to licking or lifting one hind paw. The cutoff was $30 \mathrm{~s}$.

\section{Intrathecal Administration of Naspm}

Naspm was dissolved in phosphate-buffered saline (PBS) and $5 \mu \mathrm{l}$ were injected i.t. between L5 and L6, using a $25-\mu \mathrm{l}$ Hamilton syringe and $30 \mathrm{G} \mathrm{x} 1 / 2$ inch hypodermic needles. Behavioral tests (von Frey or Rotarod) were performed 60 min later. Doses of naspm were initially selected based on previous literature (Gangadharan et al, 2011).

\section{Rotarod Test}

Mice were trained on the accelerating rotarod (IITC Life Science Inc.) on a 3-day schedule including three $5 \mathrm{~min}$ sessions per day. The first four sessions were done in constant acceleration from 4 to 20 r.p.m. over a 5 -min period. In the following sessions, rotarod acceleration was 
set from 4 to 30 r.p.m. over a 5 -min period. Latency to fall was recorded.

\section{Subcellular Fractionation}

Postsynaptic density fractions from spinal cord dorsal horns were obtained as previously described (Billa et al, 2010; Moron et al, 2007; Xia et al, 2011). Three dorsal horns from lumbar/sacral spinal cords of saline or morphinetreated mice were pooled to obtain each individual sample.

\section{Western Blotting}

Equal amounts of protein ( $15 \mu \mathrm{g}$ for homogenates, $6-8 \mu \mathrm{g}$ for postsynaptic fractions) were analyzed by SDS-polyacrylamide gel electrophoresis followed by western blotting as previously described (Xia et al, 2011). The following primary antibodies were used: anti-GluA1 (1:1000, \#MAB2263, Millipore), anti-pGluA1S845 (1:1000, \#041073, Millipore), anti-GluA2 (1:1000, \#MAB397, Millipore), anti-pGluA2Y876 ( $1: 500, \# 4027$, Cell Signaling), anti-GluA3 (1:1000, \#4676, Cell Signaling), anti-GluA4 (1:500, \#AB1508, Millipore), anti-GluA4 (1:200, \#sc-7614, Santa Cruz), anti-pGluA4S842 (1:3000, \#AB2212, Millipore), antiPSD-95 (1:1000, \#2507, Cell Signaling), anti-synaptophysin 1 (1:3000, \#101011, Synaptic Systems). Equal protein loading was ensured by re-probing the membranes with anti-actin antibody (1:10000, \#MAB1501, Millipore). Densitometry was performed using AlphaEaseFC software (ver.4.0.0, Alpha Innotech).

\section{Co-Immunoprecipitation}

A measure of $5 \mu \mathrm{g}$ of GluA1, GluA2, GluA3, or GluA4 (\#AB1508) antibody were used to immunoprecipitate AMPAR subunits from dorsal horn postsynaptic density fractions $(90-100 \mu \mathrm{g}$ ), as previously reported (Xia et al, 2011).

\section{Immunohistochemistry}

Mice were perfused with ice-cold $4 \%$ paraformaldehyde, $0.1 \%$ picric acid in $0.1 \mathrm{M}$ phosphate buffer, and L4/5 spinal cord sections removed and cut at $30-50 \mu \mathrm{m}$ on a sliding microtome. Free-floating sections from each group were processed in parallel. Sections were pretreated at $37^{\circ} \mathrm{C}$ with PBS with $0.2 \%$ Triton X-100 for 30 min followed by 3-4 min in $0.2 \mathrm{M} \mathrm{HCl}$ with $1 \mathrm{mg} / \mathrm{ml}$ pepsin (Nagy et al, 2004). After blocking in $10 \%$ normal donkey serum with $0.2 \%$ Triton $\mathrm{X}-100$, sections were incubated overnight with anti-GluA4 $(1: 1500$, \#AB1508, Millipore) in 1\% normal donkey serum with $0.2 \%$ Triton X-100 (RT).Then were incubated for $1 \mathrm{~h}$ (RT) in biotinylated anti-rabbit IgG $(1: 200$, Vector Labs) and placed in Avidin-Biotin complex (Vector Labs) before being reacted for $8 \mathrm{~min}$ with Cyanine-3-labeled tyramide amplification reagent to enhance sensitivity $(1: 75$, Perkin Elmer). Sections were rinsed with PBS between steps. Finally, were coverslipped with Vectashield (Vector Labs). Controls included immunostaining in the absence of primary antibody and preabsorption controls combining $1 \mathrm{ml}$ of antibody $(1: 1500)$ with an excess of antigen $(100 \mu \mathrm{g}$, Millipore). Both controls showed no immunoreactivity.
Color digitized images were captured using the $\times 20$ objective on an Olympus BX51 microscope coupled to a Spot-RT digital camera (Diagnostic Instruments). Integrated optical density (IOD) was measured using ImageJ software (v1.42q, NIH).

\section{Electrophysiology}

For the whole-cell patch-clamp experiments, 3- to 4-weekold mice were anesthetized with $5 \%$ isoflurane inhalation and euthanized by decapitation. Spinal cords were removed rapidly in an ice-cold cutting solution containing (mM): 235 sucrose, $2.5 \mathrm{MgSO}_{4} 7 \mathrm{H}_{2} \mathrm{O}, 2.5 \mathrm{KCl}, 1 \mathrm{NaH}_{2} \mathrm{PO}_{4}, 1 \mathrm{CaCl}_{2}, 26.2$ $\mathrm{NaHCO}_{3}$, and 11 glucose. After removal of the dura matter, all the roots were cut close to the cord and the spinal cord was embedded in low-melting point agarose (Invitrogen) for slicing (Tong and MacDermott, 2006). Transverse slices were obtained using Leica VT $1200 \mathrm{~S}$ vibrating blade microtome at a $300-\mu \mathrm{m}$ thickness, whereas the agarose block containing the spinal cord was submerged in an icecold cutting solution. Slices were transferred to beakers that contained Krebs solution and incubated at $30 \pm 1{ }^{\circ} \mathrm{C}$ for at least $1 \mathrm{~h}$. Then, slices were transferred to the recording chamber continuously perfused with Krebs solution and recordings were made at RT. Krebs solution comprised $(\mathrm{mM}): 125 \mathrm{NaCl}, 2.5 \mathrm{KCl}, 1.25 \mathrm{NaH}_{2} \mathrm{PO}_{4}, 26 \mathrm{NHCO}_{3}, 25$ glucose, $1 \mathrm{MgCl}_{2}, 2 \mathrm{CaCl}_{2}$, pH 7.4. $95 \% \mathrm{O}_{2} / 5 \% \mathrm{CO}_{2}$ was bubbled continuously during dissection, incubation, and recording.

A concentric bipolar stimulating electrode was placed in dorsal root entry zone to evoke synaptic responses. Visualized whole-cell patch-clamp recordings were made from laminae III-V of the lumbar spinal cord slices with recording pipettes containing (mM): 130 Cs-methylsulphonate, 10 Na-methylsulphonate, 10 EGTA, $1 \mathrm{CaCl}_{2}, 10$ HEPES, 5 QX-314. Cl, 0.1 spermine tetrahydrochloride, 2 $\mathrm{Mg}^{2+}$-ATP. Osmolarity was adjusted to $280-290 \mathrm{osmol} / \mathrm{l}$ and $\mathrm{pH}$ to 7.35-7.4 with $\mathrm{CsOH}$. Open pipette resistance was 2-4M , and access resistance during recordings was $<20 \mathrm{M} \Omega$. EPSCs were recorded (Axopatch 200B, Axon Instruments) in neurons voltage clamped at $-70 \mathrm{mV}$ holding potentials. To isolate AMPA-mediated responses, all the experiments were performed in the presence of $\mathrm{NMDA}, \mathrm{GABA}_{\mathrm{A}}, \mathrm{GABA}_{\mathrm{B}}$, and glycine receptor blockers: $50 \mu \mathrm{M}$ 2-amino-5-phosphonovalerate, $100 \mu \mathrm{M}$ picrotoxin, $2 \mu \mathrm{M}$ (2S)-3-[[(1S)-1-(3,4-dichlorophenyl)ethyl]amino-2hydroxypropyl](phenylmethyl)phosphinic acid hydrochloride (CGP55845), and $1 \mu \mathrm{M}$ strychnine. The records were filtered at $1 \mathrm{kHz}$. Data acquisition and analysis were performed using Clampex and Clampfit 10 (Axon Instruments). EPSCs were recorded before and after bath application of naspm (Tocris Bioscience, $100-200 \mu \mathrm{M}$ ) or IEM-1460 (Tocris Bioscience, $50 \mu \mathrm{M}$ ). The RI was calculated from I-V curves as the ratio of AMPAR-mediated EPSCs at $-60 \mathrm{mV}$ to AMPAR EPSC at $+40 \mathrm{mV}(-60 /+40 \mathrm{mV})$. Anti-GluA4 (1:2500, \#AB1508) was included in the patch pipette solution and osmolarity was adjusted. The recordings were made at least $15-20 \mathrm{~min}$ after infusion of the antibody. Inactivation of the antibody for the control experiments was achieved by heating at $95^{\circ} \mathrm{C}$ for $20 \mathrm{~min}$. 


\section{Statistical Analysis}

Data were analyzed following this rationale: Shapiro-Wilk normality test was applied to the sets of data to be compared. When normality was demonstrated, either a paired or unpaired $t$-test (behavior, immunohistochemical, and electrophysiological data) was used to do comparisons within or between groups. In the experiments with the naspm, a two-way ANOVA followed by Tukey's test was used to compare differences among the four groups. When normality was not obtained, ie, biochemical data, Mann-Whitney $U$-test was used to compare groups. In electrophysiological experiments, $n$ represents the number of animals. If more than one slice per animal was used, values from separate slices from the same animal were averaged into one value. Data are expressed as mean \pm SEM, and statistical analyses were performed using Prism (GraphPad Software) or SPSS software (ver.13.0; SPSS).

\section{RESULTS}

\section{Mechanical Hypersensitivity Following Repeated Morphine Administration}

Opioids, such as morphine, have been shown to induce hypersensitivity in a number of studies with rodents (Angst and Clark, 2006). In this study, we used a repeated drug administration procedure with escalating doses of morphine (Billa et al, 2010) and evaluated its effects on mechanical and heat sensitivity. In the pain assays, mice were first habituated to the testing environment and then evaluated until they showed stable baseline thresholds or latencies (3-5 days). The obtained baseline values were $2.1 \pm 0.4 \mathrm{~g}$ for paw withdrawal threshold to mechanical stimulation (von Frey test), $8.3 \pm 0.2 \mathrm{~s}$ for the paw withdrawal latency to heat stimulation (Hargreaves test), and $11.6 \pm 0.7 \mathrm{~s}$ for the tail-flick latency to heat stimulation (hot water tail-flick test). For the hot plate test, no baseline was established in order to avoid learned behavior (Le Bars et al, 2001). Once the baselines were determined, mice underwent a morphine or saline treatment and were evaluated $12 \mathrm{~h}$ after the final injection.
Mice treated with morphine showed a robust reduction in the mechanical threshold $12 \mathrm{~h}$ after the last injection $(42 \pm 15 \%)$. This decrease was significantly different from baseline ( $p=0.038$, paired $t$-test, Figure $1 \mathrm{a} ; n=6$ per group) and when compared with saline-treated mice $(p=0.025$, unpaired $t$-test, Figure 1a; $n=6$ per group). As opioids have been shown to induce thermal hypersensitivity in rodents (Angst and Clark, 2006), we used three different assays to evaluate heat sensitivity (Hargreaves, hot plate, and hot water tail flick tests). However, no increase in sensitivity to heat was detected $12 \mathrm{~h}$ after morphine treatment (see Figure 1b-d; $n=5-10$ per group $p>0.05$ ). Thus, we concluded that in our experimental conditions morphine induced hypersensitivity to mechanical, but not heat stimulation.

\section{Intrathecal Administration of a Selective GluA2-Lacking AMPAR Inhibitor Blocks Morphine-Induced Mechanical Hypersensitivity}

To test the hypothesis that spinal GluA2-lacking AMPAR have a role in morphine-induced mechanical hypersensitivity, we performed a set of experiments in which we administered naspm (i.t.), a specific blocker of GluA2lacking AMPAR, to morphine- and saline-treated mice.

First, we tested the effects of different doses of naspm (based on a recent study by Gangadharan et al, 2011) in morphine-treated animals. Twelve hours after the last morphine injection, mice received an i.t. injection of 0.01 , 0.1 , or $1 \mathrm{nmol}$ of naspm or its vehicle (PBS), and mechanical thresholds were evaluated $60 \mathrm{~min}$ later. Morphine-treated mice that received i.t. PBS showed significant reduction of mechanical thresholds (19\% decrease, $n=7$ per group, $p=0.024$ when compared with baseline, paired $t$-test, $t_{(6)}=3.014$, Figure 2a); however the mechanical thresholds in mice treated with $0.01,0.1$, or $1 \mathrm{nmol}$ of naspm were not different from baseline (Figure 2a). To avoid unspecific effects, we selected the dose of $0.01 \mathrm{nmol}$ naspm to conduct a more complete experiment including appropriate controls. Twelve hours after the treatment, morphine- or salinetreated mice received an i.t. injection of $0.01 \mathrm{nmol}$ of naspm or PBS. In this experiment, the baseline value for the paw
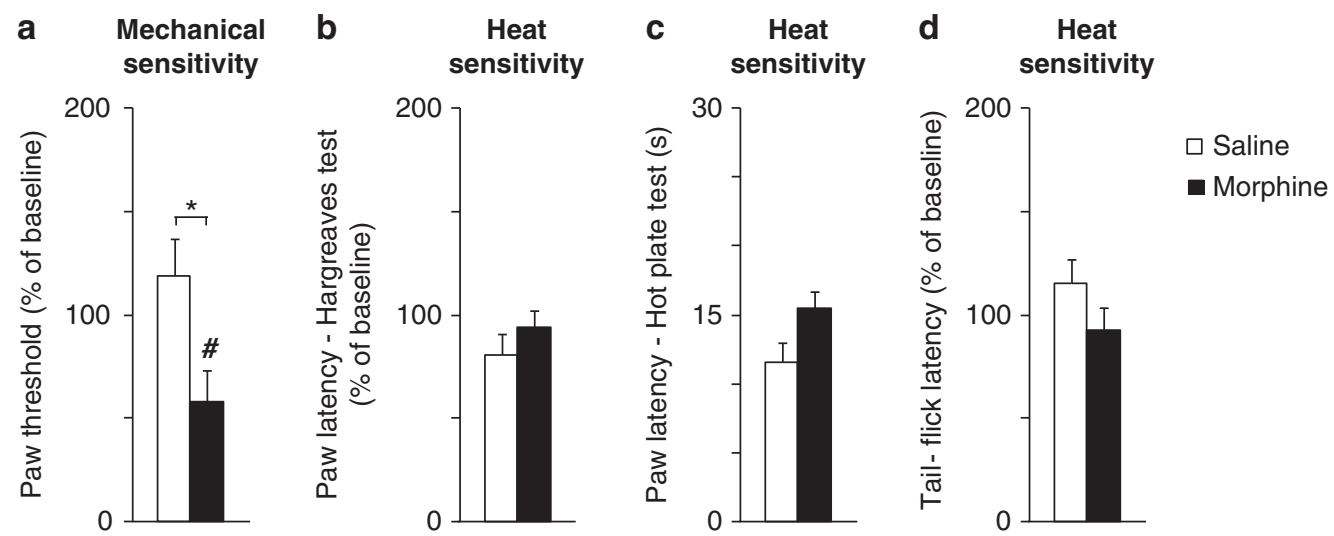

Figure I Repeated morphine induces pain sensitivity to mechanical stimuli. Measurements are taken $12 \mathrm{~h}$ after repeated saline ( $\square$ ) or morphine administration ( $)$. Values are expressed as mean \% \pm SEM from baseline, set to 100 (a, b, d), except for the hot plate test, which shows raw data (c). (a) Mechanical paw thresholds measured with von Frey test, $n=6$. (b) Paw withdrawal latencies to heat stimulation, Hargreaves test, $n=6$.(c) Paw withdrawal latencies to heat stimulation, hot plate test, $n=6-7$. (d) tail-flick latencies to heat stimulation, hot tail immersion test, $n=6-7$. $* P<0.05$, saline $v s$ morphine; unpaired t-test. ${ }^{\#} P<0.05$, vs baseline, paired t-test. 

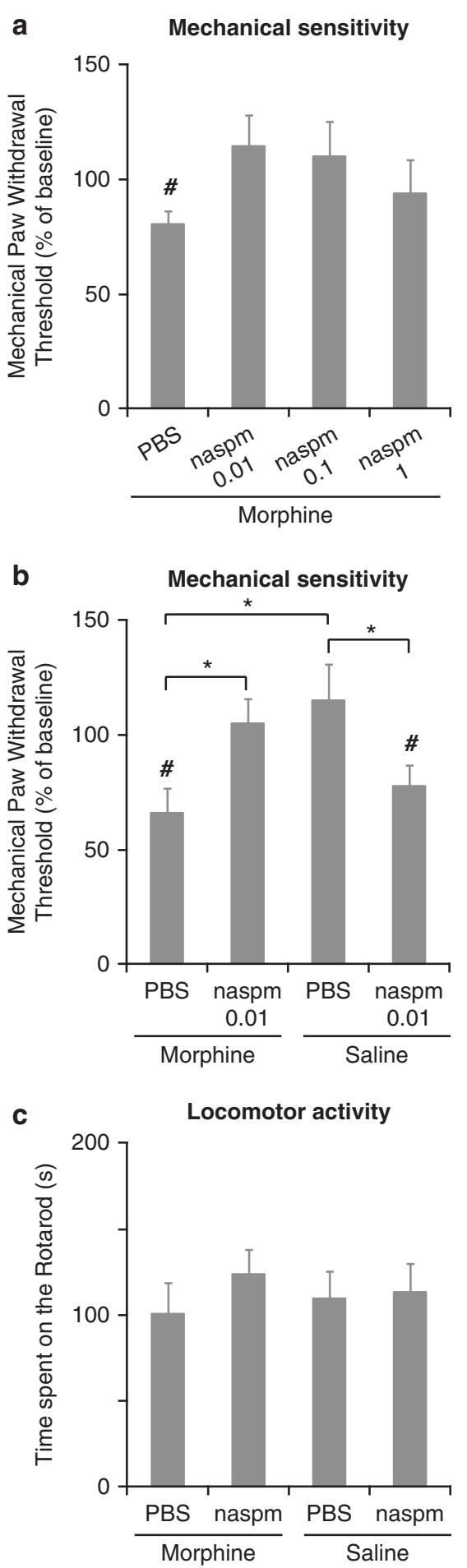

Figure 2 Intrathecal administration of naspm reverses mechanical hypersensitivity in morphine-treated mice. Twelve hours after repeated morphine or saline administration, mice are injected i.t. with PBS or naspm and evaluated 60 min later. (a) Dose-response relationship for naspm in morphine-treated mice. The PBS group was significantly different from baseline but all naspm groups were not; ${ }^{\#} p<0.05$, vs baseline, paired $t$-test. (b) 0.01 nmol of naspm reversed mechanical hypersensitivity in morphine-treated mice. The same dose induced a decrease in mechanical thresholds in mice that were not exposed to morphine. Values are expressed as mean $\% \pm$ SEM from the baseline, set to $100 ; n=7$, $* p<0.05$, two-way ANOVA followed by Tukey's test; ${ }^{*} p<0.05$, vs baseline, paired $t$-test. (c) Motor functions are evaluated by measuring the latency to fall (in s) on the accelerating rotarod. Latencies are similar in all the groups. Values are expressed as mean $\% \pm$ SEM, $n=7-9$ mice per group, $p>0.05$, two-way ANOVA. withdrawal threshold was $1.61 \pm 0.06 \mathrm{~g}$. Morphine-treated mice that received $0.01 \mathrm{nmol}$ of naspm i.t. showed a reversal of morphine-induced mechanical sensitivity $(5 \pm 8 \%$ increase from baseline; Figure 2b; $n=7$ per group; $p=0.047$ when compared with morphine-treated mice that received PBS, two-way ANOVA followed by Tukey's test). As expected, mice treated with morphine that received i.t. PBS showed a reduction in mechanical threshold (34 $\pm 8 \%$ decrease, Figure $2 \mathrm{~b} ; n=7$ per group); this reduction was significant when compared with baseline $(p=0.009$, paired $t$-test, $t_{(6)}=3.842$, Figure $2 \mathrm{~b}$ ) and when compared with saline-treated mice that received PBS $(p=0.002$, two-way ANOVA followed by Tukey's test). Unexpectedly, salinetreated mice treated with naspm developed mechanical hypersensitivity ( $22 \pm 8 \%$ decrease, Figure $2 \mathrm{~b} ; n=7$ per group). This reduction in threshold was significant when compared with baseline ( $p=0.032$, paired $t$-test, $t_{(6)}=3.842$, Figure $2 b$ ) and when compared with saline-treated mice that received PBS $(p=0.023$, two-way ANOVA followed by Tukey's test). Indeed, the two-way ANOVA test revealed an interaction between morphine and naspm treatments $\left(\mathrm{F}_{(1,6)}=20.109 ; p<0.001\right)$.

To determine whether the administration of naspm and/ or morphine could have an effect on motor functions, the rotarod test was used at the same time point in which mechanical sensitivity was assessed. We did not observe differences in the time spent over the rotarod among the different groups (Figure 2c; $n=7-9$ mice per group; $p>0.05$, two-way ANOVA). Overall, these results show that blockade of spinal GluA2-lacking AMPAR by naspm completely reverses the mechanical hypersensitivity observed following discontinuation of morphine treatment. Surprisingly, the same drug induces mechanical hypersensitivity in mice that have not been exposed to morphine. Therefore, these data suggest that morphine administration alters the expression or composition of GluA2-lacking AMPAR in the spinal cord dorsal horn.

\section{The Expression and Phosphorylation Levels of AMPAR Subunits are Altered in the Dorsal Horn Following Repeated Morphine Treatment}

We have shown that repeated morphine administration produces mechanical hypersensitivity $12 \mathrm{~h}$ after the treatment. Data shown above suggest a role for $\mathrm{Ca}^{2+}$ - permeable AMPAR in this behavioral effect. To investigate this, we assessed changes in expression and phosphorylation of AMPAR subunits in homogenates from spinal cord dorsal horns $12 \mathrm{~h}$ following the last morphine or saline injection. We observed a dramatic increase in GluA4 expression (62 $\pm 9 \%$ increase; Figure 3a; $n=6$ per group; $p=0.004$ when compared with saline-treated mice, Mann-Whitney $U$-test), however, the levels of GluA1, GluA2, or GluA3 were not altered (Figure 3a; $n=5$ per group; $p>0.05$ when compared with saline-treated mice, Mann-Whitney $U$-test). Interestingly, phosphorylation levels of GluA1 and GluA2 were increased in morphine-treated animals $(51 \pm 6 \%$ and $54 \pm 3 \%$, respectively; Figure $3 \mathrm{~b} ; n=5$ per group; $p=0.05$ and $p=0.046$, saline $v s$ morphine, Mann-Whitney $U$-test), but no changes were observed in the level of GluA4 phosphorylation (Figure 3b; $n=5-6$ per group; $p>0.05$ 


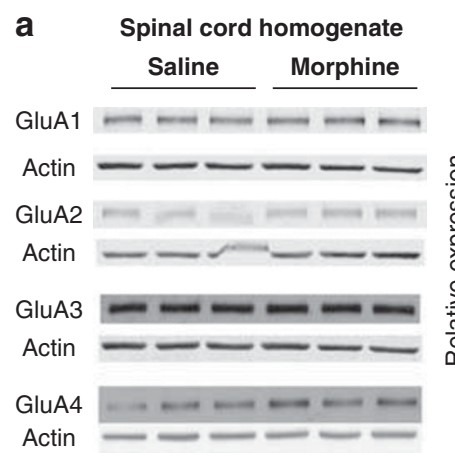

b Spinal cord homogenate
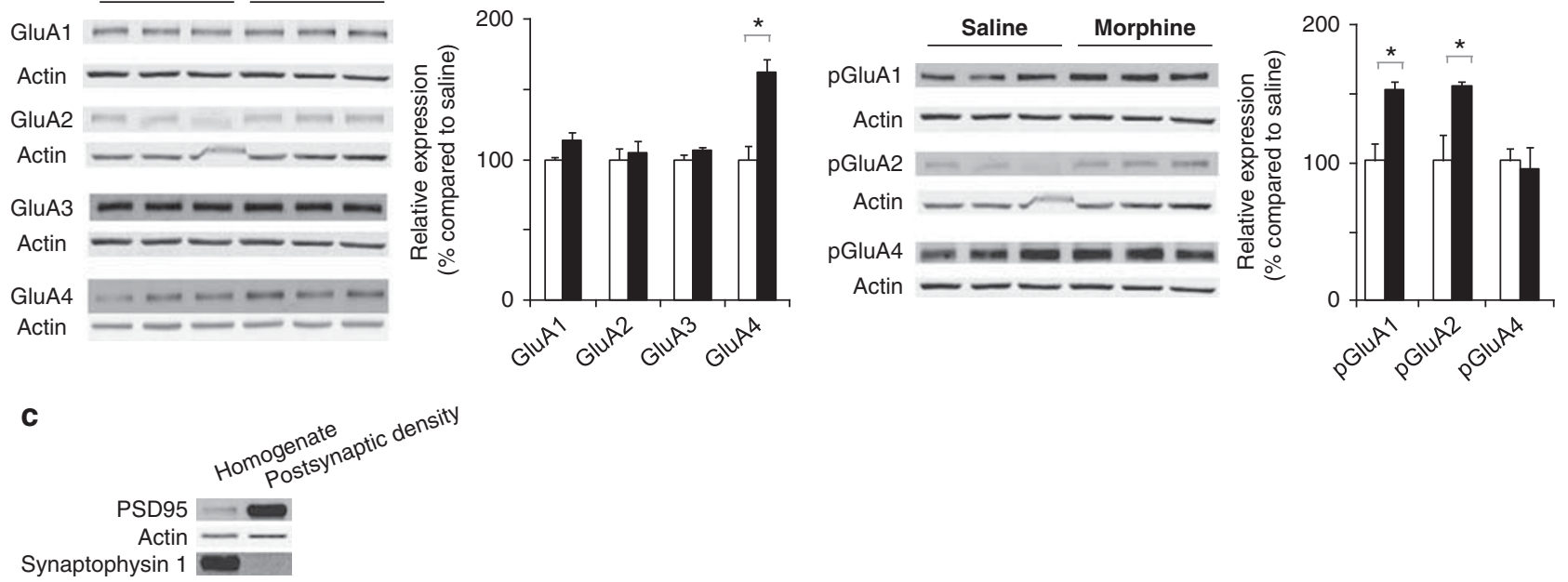
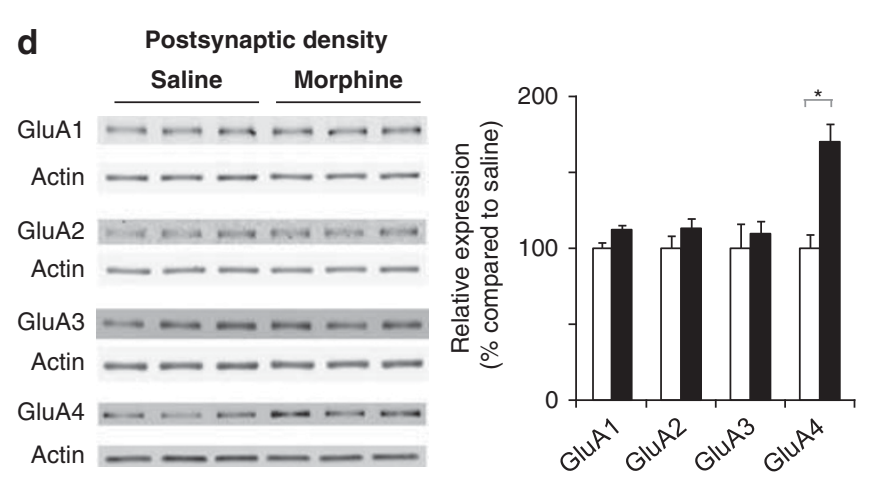
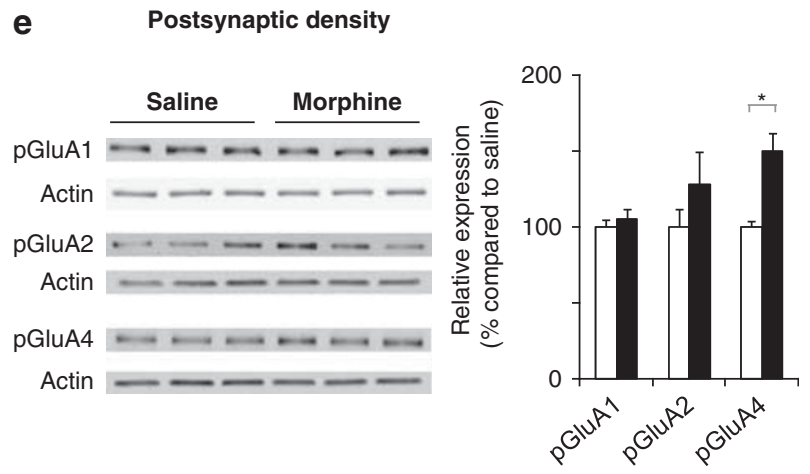

Figure 3 Morphine alters AMPAR subunit expression and phosphorylation in homogenates from the spinal cord dorsal horn, and promotes insertion of GluA4-contanining AMPAR in the postsynaptic density of dorsal horns. (a) Morphine ( $\mathbf{a})$, but not saline ( $\square$ ) increases GluA4 expression in homogenates from the spinal cord dorsal horn. (b) Morphine induces an increase in the phosphorylation levels of GluAI and GluA2 in dorsal horn homogenates. (c) Subcellular fractionation. A representative western blot shows enrichment of PSD-95 (postsynaptic marker) and the absence of synaptophysin-I (presynaptic marker) in postsynaptic density fractions from dorsal horns. (d) Morphine promotes the insertion of GluA4 at the postsynaptic density and (e) increases phosphorylation levels of GluA4. Quantification was performed relative to actin levels. Representative blots are shown. Values are expressed as mean \% \pm SEM compared with the saline group, $n=5-6$ samples per group, *p $\leqslant 0.05$, Mann-Whitney U-test.

when compared with saline-treated mice, Mann-Whitney $U$-test).

To examine whether the observed changes in expression and phosphorylation occurred at the synaptic level, we adapted our previously reported subcellular fractionation protocol (Moron et al, 2007; Xia et al, 2011) to obtain a fraction enriched in the postsynaptic density from the dorsal horns. Western blotting performed with an antibody to PSD95, a specific marker of the postsynaptic density in excitatory synapses (Okabe et al, 2001), showed that the fractionation protocol yielded a postsynaptic fraction that was enriched in PSD95 (Figure 3c), 6.5 times when compared with the homogenate. Moreover, the postsynaptic fraction showed no significant immunoreactivity to synaptophysin-I, a presynaptic marker (Okabe et al, 2001; Figure $3 \mathrm{c}$ ). This confirms the feasibility of using this fractionation protocol to obtain a highly enriched postsynaptic density fraction from dorsal horns, which is devoid of presynaptic contaminants.
Biochemical analysis of postsynaptic density fractions $12 \mathrm{~h}$ following morphine treatment revealed robust increases in the postsynaptic expression and phosphorylation of GluA4 $(70 \pm 12 \%$ and $50 \pm 12 \%$, respectively; Figure $3 \mathrm{~d}$ and e; $n=5$ per group; $p=0.009$ when compared with saline, MannWhitney $U$-test). However, no changes were observed in the expression of GluA1, GluA2, or GluA3, or in the phosphorylation levels of GluA1 or GluA2 (Figure 3d-e; $n=5$ per group; $p>0.05$, Mann-Whitney $U$-test). Taken together, these data show that following discontinuation of morphine treatment there is an increase in the postsynaptic expression and phosphorylation levels of GluA4, suggesting a role for synaptic GluA4 in the onset of morphine-induced hypersensitivity. In addition, we also observe an increase in the phosphorylation levels of GluA1 and GluA2 in total homogenates, however, no changes in the phosphorylation levels of these subunits were observed at the postsynaptic density fraction, which suggests that this effect may occur at extrasynaptic sites. 
Repeated Morphine Administration Alters the Composition of GluA4-Contaning AMPAR at Dorsal Horn Synapses

The observed increase in the expression and phosphorylation levels of GluA4 at the postsynaptic density following morphine treatment suggests a change in AMPAR composition at the synapse. Therefore, we performed co-immunoprecipitation assays in the postsynaptic density fractions of dorsal horns to directly analyze the effects of morphine on the association between GluA4 and the other AMPAR subunits. First, we examined the basal composition of GluA4-containing AMPAR in the postsynaptic density fractions. GluA1, GluA2, and GluA3 were immunoprecipitated and their association with the GluA4 subunit was assessed by western blotting (Figure 4a). An association was observed between GluA4 and GluA2 and between GluA4 and GluA3, but we could not detect a GluA4-GluA1 interaction. This is in agreement with previous studies showing that GluA1 and GluA4 are expressed by different neuronal populations in the spinal cord (Polgar et al, 2008b; Todd et al, 2009).

Next, we examined the effects of morphine on the association of GluA4 with GluA2 and GluA3. Twelve hours after discontinuation of morphine treatment GluA4 was immunoprecipitated and the levels of associated GluA2 or GluA3 were analyzed by western blotting. Morphine treatment promoted a decrease in the association between GluA4 and GluA2 (46 $\pm 15 \%$ decrease compared with salinetreated mice; Figure $4 \mathrm{~b} ; n=3$ per group; $p=0.05$, MannWhitney $U$-test). In contrast, the association between GluA4 and GluA3 was not altered following morphine administration (Figure $4 \mathrm{~b} ; n=3$ per group; $p=0.827$, Mann-Whitney $U$-test). As we did not observe any changes in the postsynaptic levels of GluA2 or GluA3 (see Figure 3d) following morphine treatment, and given that morphine increased the levels of GluA4 in this fraction (see Figure 3d), data obtained from the co-immunoprecipitation analyses suggest that morphine treatment could promote an increased insertion of GluA4 homomers (GluA2-lacking AMPAR) at the postsynaptic density of the dorsal horn spinal cord.

To rule out the possibility that morphine could trigger an increase in the interaction between GluA2 and GluA3, we conducted additional co-immunoprecipitation analyses of these subunits. First, we observed that in naive mice GluA2 exhibited a weak association with GluA3 (Figure $4 \mathrm{~b}$, right panel). Moreover, morphine treatment did not alter the association between GluA3 and GluA2 (Figure 4c). These findings further support the idea that morphine treatment triggers an increase in GluA4 homomers at the postsynaptic density of dorsal horns.

\section{The Increase in GluA4-Containing AMPAR Following Morphine Treatment is Localized in Laminae III-V of the Dorsal Horn}

To visualize the distribution of the GluA4-containing receptors in the dorsal horn, we used a GluA4-directed antibody to immunostain tissue sections taken from the saline- and morphine-treated groups $12 \mathrm{~h}$ following morphine treatment. Analysis of the IOD demonstrated that compared with the saline group, morphine-treated mice had a significant increase in the density of GluA4 staining, localized in laminae III-V (Figure $4 \mathrm{~d} ; n=12$ per group; $t_{(11)}=17 ; p=0.008$, unpaired $t$-test). In these laminae, a higher magnification picture showed numerous puncta outlining the cell bodies, which is consistent with the receptors having a postsynaptic location (Figure 4e). The superficial dorsal horn (laminae I-II) was relatively devoid of GluA4 staining in both saline and morphine-treated mice (Figure $4 \mathrm{~d}$ ).

\section{Patch-Clamp Recordings from Laminae III-V Neurons Show Increased GluA4-Containing AMPAR Contribution to the Evoked EPSCs Following Morphine Treatment}

To test whether morphine-induced alterations in AMPAR expression at the dorsal horn synapses can lead to functional changes in AMPAR-mediated synaptic transmission, we performed whole-cell patch-clamp recordings from laminae III-V neurons in spinal cord slices obtained from morphine- and saline-treated mice $12 \mathrm{~h}$ following treatment (Figure 5). Bath application of naspm, significantly reduced the amplitude of evoked EPSCs in slices from morphinetreated animals by $41.3 \pm 3.2 \%$ (Figure $5 \mathrm{~b} ; n=4$ per group; $p=0.004$ when compared with saline, Mann-Whitney $U$-test), whereas in the slices from saline-treated mice naspm reduced EPSC amplitude only by $8.6 \pm 6.4 \%$ (Figure $5 \mathrm{~b} ; n=4$ per group). Increased sensitivity to naspm suggests synaptic insertion of GluA2-lacking AMPAR receptors in the dorsal horn. To further confirm this, we used another blocker of GluA2-lacking AMPAR, IEM-1460, which has been demonstrated to rapidly and reversibly block $\mathrm{Ca}^{2+}$-permeable AMPAR in both brain and the spinal cord slices (Buldakova et al, 2007; Kopach et al, 2011). Similar to naspm, bath applied IEM-1460 $(50 \mu \mathrm{M})$ produced significantly higher inhibition of AMPAR-mediated EPSCs in the slices from morphine- $(48 \pm 9.5 \% ; n=5 ; p=0.008)$ compared with saline-treated $(7.8 \pm 3.2 \% ; n=4)$ mice (Figure $5 \mathrm{c}$ ). Next, we studied current-voltage relationships of the AMPAR-mediated EPSCs in order to further confirm these findings. RI, an indicator of $\mathrm{Ca}^{2+}$-permeable receptor contribution, was calculated from I-V curves as the ratio of AMPAR-mediated EPSCs $(-60 /+40 \mathrm{mV})$. Neurons in laminae III-V contain a mixture of $\mathrm{Ca}^{2+}$-permeable and non-permeable AMPARs (Tong and MacDermott, 2006), therefore, it was not surprising that some of the I-V curves recorded in this area in saline-treated animals showed inward rectification ( $\mathrm{RI}=1.795 \pm 0.2616, n=4$, Figure $5 \mathrm{~d}$ ). However, RI increased dramatically in morphine-treated mice $(\mathrm{RI}=3.522 \pm 0.3133, n=5, p=0.0047$ when compared with saline, unpaired $t$-test; Figure $5 \mathrm{~d}$ ). Our biochemical and immunohistochemical experiments suggest that the AMPAR increasing after morphine treatment are GluA4 homomers. As selective GluA4 antagonists have not yet been developed, to further confirm our finding we tested whether a GluA4 antibody (1:2500, \#AB1508, Millipore) could intracellularly block GluA4-containing AMPAR in morphine-treated mice. The antibody was included in the patch pipette solution. Recordings were made at least 15-20 min after infusion of the antibody. RI studied in dorsal horn neurons from morphine-treated animals 
a

IB: GluA4

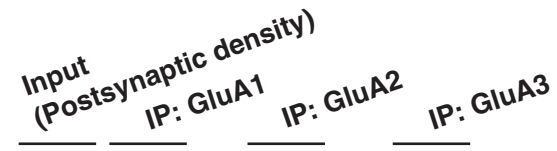

IB: GluA2

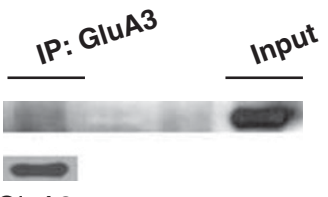

IB: GluA 1 GluA2 GluA3

IB: GluA3

b

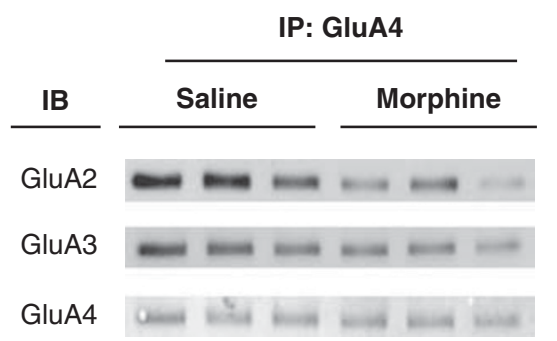

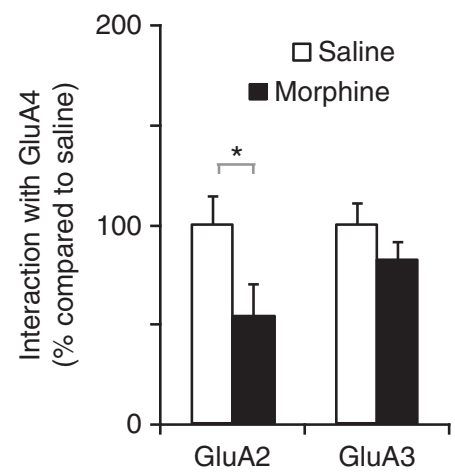

C

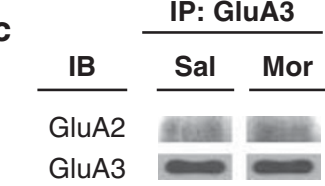

d
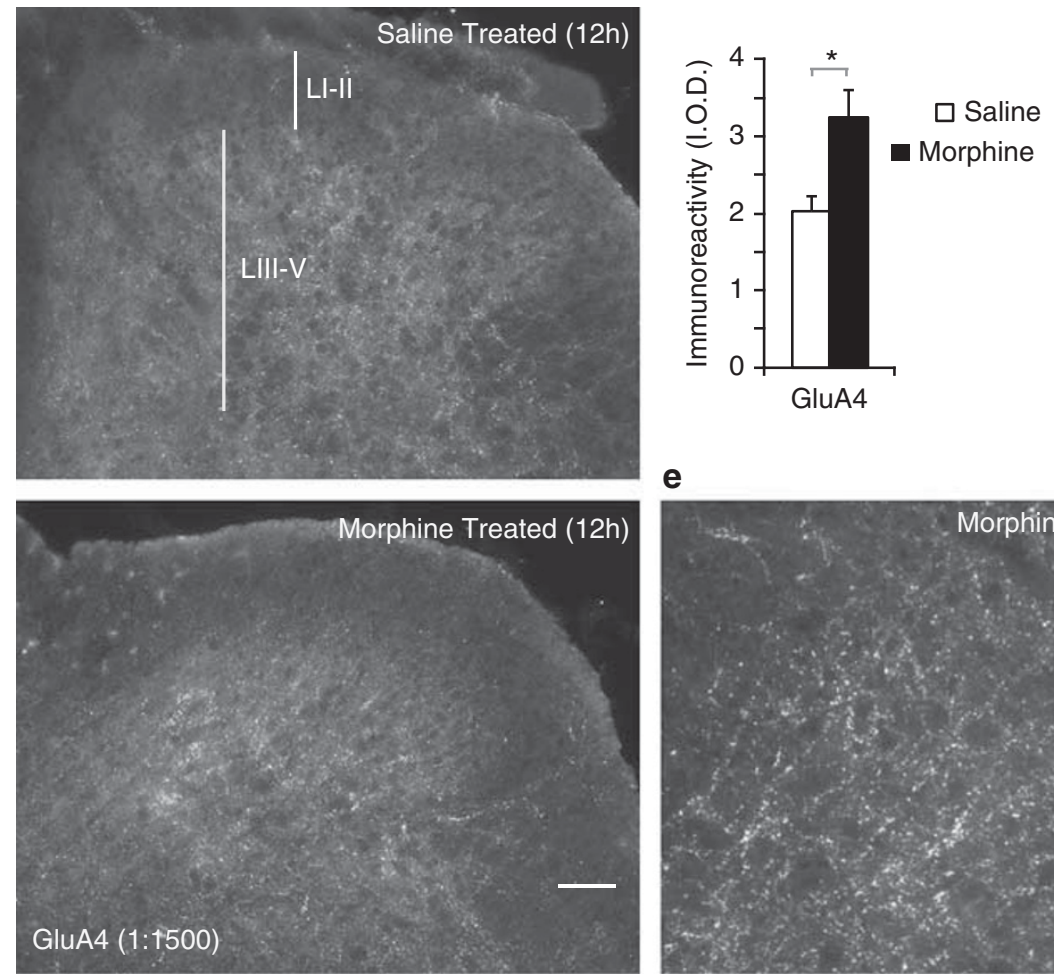

e

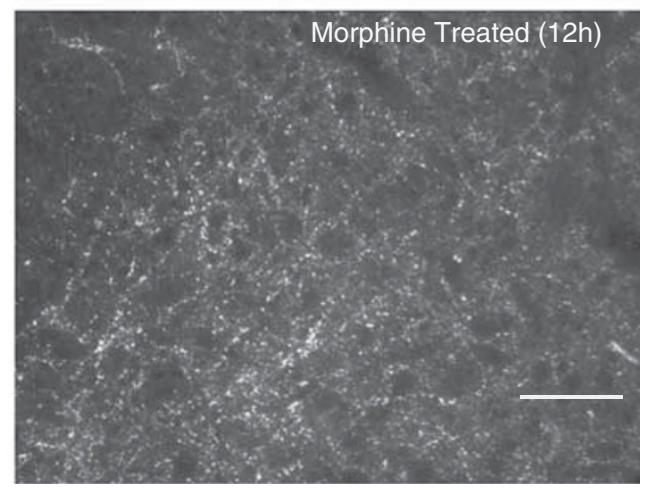

Figure 4 Composition of postsynaptic GluA4-containing AMPAR is altered after morphine treatment. The increase in GluA4-containing AMPAR is located in laminae III-V of spinal cord dorsal horn. (a) Basal composition of GluA4-containing AMPARs in the postsynaptic density. Co-immunoprecipitation of GluAI, GluA2, and GluA3 with GluA4 shows that in naive animals, GluA4 is associated with GluA2 and GluA3, however, association between GluA4 and GluAI is not detected. GluA2 exhibits weak association with GluA3. (b) The proportion of GluA4 associated with GluA2 is decreased $12 \mathrm{~h}$ after morphine ( $)$, but not saline $(\square)$ treatment, whereas the association between GluA4 and GluA3 remains unaltered. Quantification was performed relative to GluA4 levels detected in the pull down. Values are expressed as mean \% \pm SEM compared with the saline group, $n=3$ samples per group, * $p \leqslant 0.05$, MannWhitney U-test. (c) The proportion of GluA2 associated with GluA3 did not change after morphine treatment. Quantification was performed relative to GluA3 levels detected in the pull down. (d) The increase in GluA4 expression is located in dorsal horn laminae III-V, morphine ( $\mathbf{\square})$ saline ( $\square$ ), values represent IOD (means $\pm S E M) n=12$, $* p<0.0$ I, unpaired $t$-test. (e) Representative higher magnification image of GluA4 staining in dorsal horn laminae III-V from morphine-treated mouse. Immunostained puncta outline cell bodies in these laminae, consistent with the receptor having a postsynaptic location. Scale bars $=10 \mu \mathrm{m}$. 
showed that the GluA4 antibody completely reversed the inward rectification observed after morphine $(\mathrm{RI}=1.752 \pm$ $0.1086, n=5)$, whereas heat-inactivated antibody had no effect on the AMPAR-mediated EPSCs (RI $=3.392 \pm 0.2626$, $n=4, p<0.0004$, unpaired $t$-test; Figure 5e). Furthermore, to investigate whether the increased sensitivity of EPSCs to naspm in spinal cord slices from morphine-treated mice (see Figure $5 \mathrm{~b}$ ) was mediated by GluA4-containing AMPAR, we conducted additional studies in which the effects of naspm were analyzed in the presence of GluA4 antibody. Infusion of GluA4 antibody through patch pipette reversed the effect of bath applied naspm on EPSCs recorded in the slices from morphine-treated mice (Figure 5b). In the presence of GluA4 antibody, naspminduced inhibition of the EPSC amplitude was significantly lower $(12.5 \pm 2.9 \%, n=4, p=0.0006)$, and not significantly different from saline values $(p=0.6)$. These data provide direct evidence of the increased contribution of GluA4containing receptors to AMPAR-mediated EPSCs following morphine treatment in neurons from laminae III-V of the dorsal horn.

\section{DISCUSSION}

In this study, we provide evidence that spinal cord $\mathrm{Ca}^{2+}$. permeable AMPAR (and more specifically GluA4-containing AMPAR) mediate the early stages of morphine-induced pain sensitivity. We show that the administration of escalating doses of morphine triggers mechanical hypersensitivity. This is in agreement with a number of previous studies reporting the development of hypersensitivity following morphine treatment in rodents (Angst and Clark, 2006; Liang et al, 2008; Liang et al, 2011; Muscoli et al, 2010; Vera-Portocarrero et al, 2007). Sensory sensitization induced by opioids has also been reported in clinical studies showing an increase in mechanical sensitivity after repeated exposure to morphine (Chu et al, 2006; Hay et al, 2009). The fact that our morphine treatment procedure did not elicit an increase in heat sensitivity is consistent with other reports suggesting that opioids can sensitize the nociceptive pathways activated by mechanical stimuli to a greater extent than those activated by heat stimuli (Angst and Clark, 2006; Cabañero et al, 2009). Indeed, the morphine regimen used in this study was previously shown not to elicit heat sensitization in rats (Gendron et al, 2007).

To elucidate the contribution of spinal AMPAR to the early stages of morphine-induced pain sensitivity, we next studied the effects of the selective GluA2-lacking AMPAR $\left(\mathrm{Ca}^{2+}\right.$-permeable) blocker, naspm, on morphine-induced mechanical sensitivity. Interestingly, we found that i.t. administration of a low dose of naspm $(0.01 \mathrm{nmol}) 12 \mathrm{~h}$ following morphine treatment completely reversed morphine-induced mechanical sensitivity without altering motor functions. A recent study demonstrated that peripheral administration of higher doses of naspm (0.1-41.6 nmol) attenuated mechanical hypersensitivity in a mouse model of chronic inflammatory pain (Gangadharan et al, 2011). Although morphine- and CFA-induced hypersensitivity constitute different pain models, our results suggest that lower doses of naspm have similar efficacy when administered i.t. Our data also show that the administration of naspm decreased the mechanical thresholds in saline-treated animals. These results differ from the study by Gangadharan et al (2011) in which naspm was administered peripherally and no effect of naspm on mechanosensitivity was observed in control animals. This discrepancy could be partially explained by the different route of administration used in this study. On the other hand, our data suggest that AMPAR have different composition after repeated morphine treatment.

An increase in GluA4 subunit expression is detected in dorsal horn homogenates $12 \mathrm{~h}$ following discontinuation of morphine treatment. In addition, expression and phosphorylation levels of GluA4 are significantly increased in the postsynaptic density at the same time point. Previous studies have suggested that GluA4-GluA2 heteromers are highly abundant in laminae III-V (Polgar et al, 2008b; Todd et al, 2009). In agreement with these studies, our immunohistochemical analyses localized GluA4-containing AMPAR in laminae III-V (Figure 4d). The observed perikaryal distribution of GluA4 puncta (Figure 4e) further supports the postsynaptic localization of GluA4. We also observed that morphine treatment induced an increase in GluA4-immunoreactive puncta in laminae III-V (Figure 4d). Taking into account that the proportion of GluA4-GluA2 heteromers at the postsynaptic density is decreased in morphine-treated mice (Figure $4 \mathrm{~b}$ ), and that postsynaptic GluA2 and GluA3 levels, as well as their

\footnotetext{
Figure 5 Whole-cell patch-clamp recordings indicate morphine-induced insertion of GluA4-containing AMPAR in laminae III-V of spinal cord dorsal horn. (a) The spinal cord slice cartoon shows positioning of the electrodes. (b) AMPAR-mediated EPSCs show increased sensitivity to naspm in spinal cord slices from morphine-treated animals, which is reversed by infusion of GluA4 antibody. Sample traces (average of 20 trials) were recorded before and after naspm application (I00 $\mu \mathrm{M}$ ). Histograms show an average percentage inhibition (means \pm SEM) of EPSCs. (c) The effect of another Ca ${ }^{2+}$-permeable AMPAR blocker, IEM-I460, in slices from morphine-treated mice is similar to naspm. The amplitude of AMPAR-mediated EPSCs is plotted against time (left panel) and the histogram shows average percentage inhibition (right panel). Sample traces (average of 20 trials) were recorded before and after IEM-I460 application $(50 \mu \mathrm{M})$. (d) Current-voltage relationships obtained by plotting AMPAR-EPSC amplitude as a function of holding potential (average I-V curves are shown). In saline-treated animal, I-V curves are almost linear showing very little contribution of $\mathrm{Ca}^{2+}$-permeable AMPAR. I-V curves obtained from a morphine-treated animal shows inward rectification - an indicator of $\mathrm{Ca}^{2+}$-permeable AMPAR insertion. Average RI calculated as EPSC ( $-60 /+40 \mathrm{mV}$ ) is increased by morphine compared with saline. (e) I-V curve in morphine-treated animal is not affected by heat-inactivated anti-GluA4 included in the patch solution. Anti-GluA4 included in patch solution restores linearity of I- $\mathrm{V}$ curve from a morphine-treated animal. Average RI recorded from the slices of morphine-treated mice in the presence of heat-inactivated anti-GluA4 is similar to RI recorded without antibody. Anti-GluA4 included in the pipette completely reverses $\mathrm{RI}$ to the levels recorded in saline-treated mice, showing that $\mathrm{Ca}^{2+}$-permeable AMPARs inserted at the synapse after morphine consist of GluA4 subunits. $* p<0.05$.
} 
a

b

Dorsal root entry zon stimulation
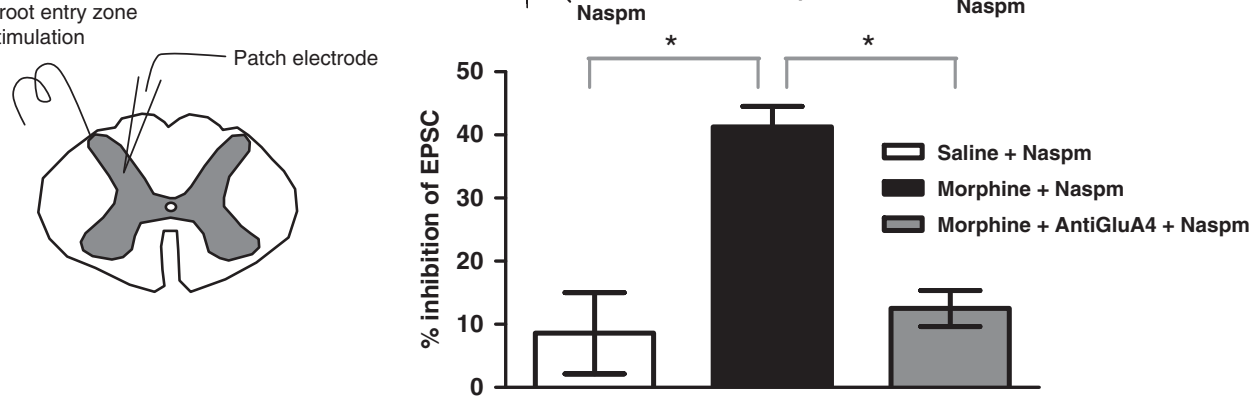<smiles>IC12CC3CC(CC(C3)C1(I)C1CCCCC1)C2</smiles>
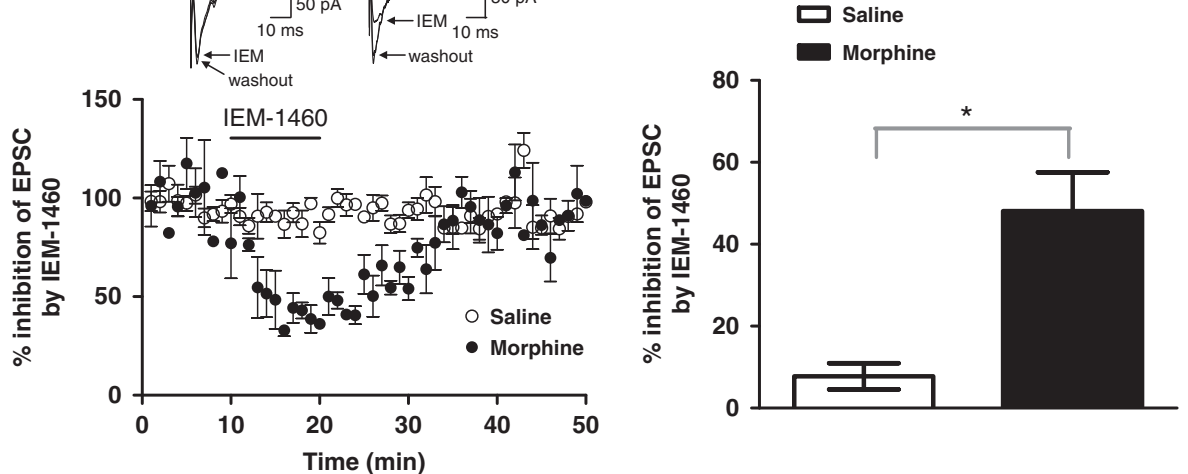

d
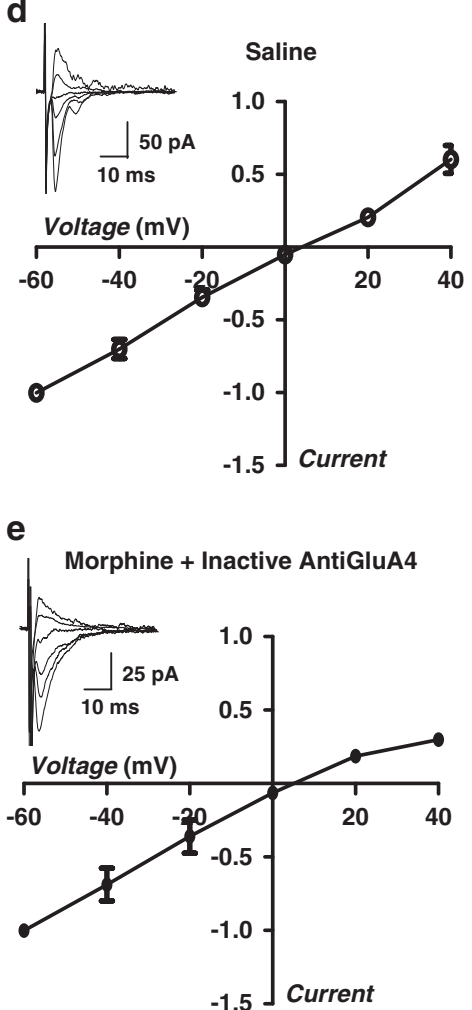

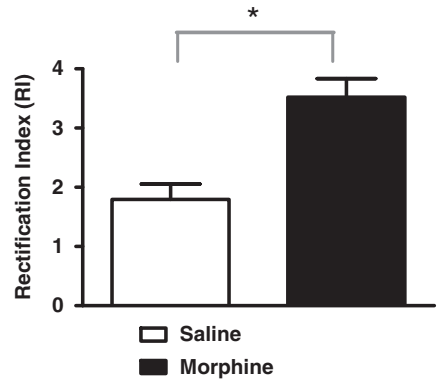

-1.5 Current
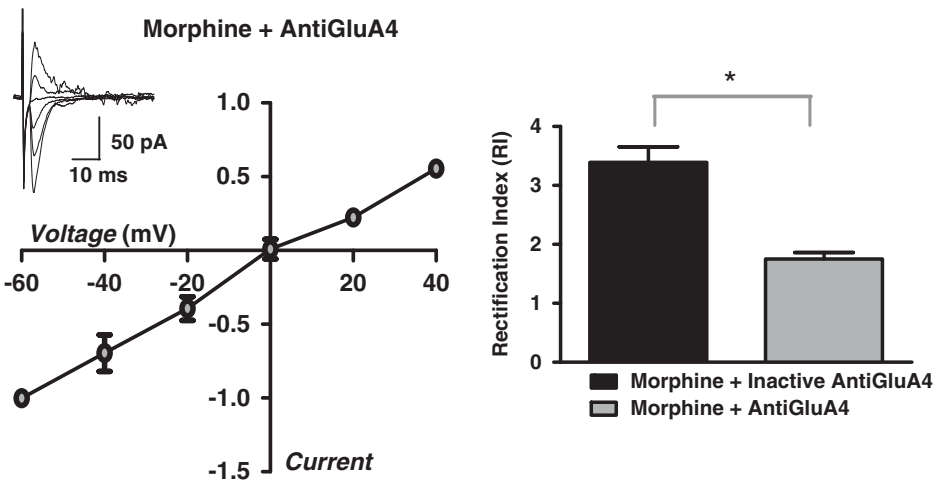
association, do not change (Figure 4c); the observed increase in expression of GluA4 suggests an increased insertion of GluA4 homomers at the synapse following morphine treatment. Whole-cell patch-clamp recordings from laminae III-V neurons provide further evidence for the insertion of $\mathrm{Ca}^{2+}$-permeable AMPAR at the dorsal horn synapses. Taken together, our results suggest that insertion of GluA2-lacking AMPAR in the spinal cord can account for the hypersensitivity observed following discontinuation of morphine treatment. This is supported by our data showing that the i.t. administration of the GluA2-lacking AMPAR blocker, naspm, reverses morphine-induced mechanical sensitivity, providing proof of concept for the role of spinal cord AMPAR in morphine-induced pain sensitivity.

Morphine treatment also resulted in an increase in GluA1/2 phosphorylation in the homogenate, but this effect was not observed in the postsynaptic density fraction suggesting that the increase was localized at extrasynaptic sites. GluA1 phosphorylation at Ser845 by cyclic adenosinemonophosphate-dependent protein kinase A (PKA) triggers postsynaptic insertion of the receptors containing this subunit (Man et al, 2007). Similarly, GluA4 phosphorylation at Ser842 by PKA promotes insertion of GluA4-containing AMPAR (Esteban et al, 2003). Therefore, PKA-mediated phosphorylation of GluA1 and GluA4 can represent one of the underlying mechanisms of morphine-induced hypersensitivity. A recent study using PKA-selective small interference RNA confirms that PKA activity in the spinal cord is essential for the development of morphine-induced hypersensitivity (Tumati et al, 2011). GluA4 can also be phosphorylated at Ser842 by PKC- $\gamma$ (Gomes et al, 2007; Zheng and Keifer, 2008). Deletion of the gene encoding PKC- $\gamma$ abolishes opioid-induced hypersensitivity (Célérier et al, 2004), whereas repeated administration of $\mu$-opioid agonists increases PKC- $\gamma$ activity (Chakrabarti et al, 2005; Narita et al, 2001). Thus, PKC- $\gamma$ may represent an additional key player in the regulation of trafficking of GluA4containing AMPAR by opioids. The functional implication of the increase in GluA1/2 phosphorylation would be an increased insertion of GluA1 into the membrane and an increased internalization of GluA2-containing AMPAR, which can lead to an overall increase in $\mathrm{Ca}^{2+}$-permeable AMPAR (Malinow and Malenka, 2002). Recent studies have demonstrated that an increase in GluA1/2 phosphorylation at extrasynaptic sites underlies the development of inflammatory pain (Kopach et al, 2011). Overall, our data support the idea that opioid treatment and chronic inflammation can induce hypersensitivity by similar mechanisms.

Although the role of GluA1 and GluA2 in sensory sensitization has been extensively studied over the last few years (Atianjoh et al, 2010; Kopach et al, 2011; Nagy et al, 2004; Park et al, 2009; Youn et al, 2008), the role of GluA4 in pain-associated mechanisms remains elusive. Our immunohistochemical analyses show that morphine treatment resulted in an increase of GluA4 expression in laminae III-V. Interestingly, Polgar et al (2008b) reported that GluA4-immunoreactive neurons are GluA1-negative, suggesting that GluA1 and GluA4 are present in different neuronal populations. The observed lack of association between GluA4 and GluA1 revealed by our co-immunoprecipitation analyses is in agreement with their findings. In the dorsal horn, GluA4 is mainly expressed at synapses of two types of projection neurons: large gephyrin-coated projection neurons in lamina I and neurokinin-1 receptor (NK1R)-positive neurons in laminae III-V (Polgar et al, 2008a; Todd et al, 2009). As the specific ablation of projection neurons expressing NK1R completely prevents morphine-induced hyperalgesia (Vera-Portocarrero et al, 2007), it is likely that the increase in GluA4 could have a role in the development of nociceptive sensitivity after morphine. This is supported by our data showing that the direct application of an anti-GluA4 antibody through patch pipette in laminae III-V neurons completely reverses morphine-induced alterations in AMPAR-mediated currents.

These neurons constitute the ascending limb of a spinal-bulbospinal loop that triggers descending facilitation and promotes neuroplasticity in the dorsal horn (Vera-Portocarrero et al, 2007). GluA4-positive neurons have been found to receive a much higher density of glutamatergic inputs compared to neurons expressing GluA1 (Polgar et al, 2010; Todd et al, 2009). This suggests different roles for GluA1 and GluA4 during the development of central sensitization. The fact that GluA1 and GluA4 have been related to different forms of long-term potentiation supports this idea (Boehm and Malinow, 2005). Our findings point to an important role for GluA4-containing AMPAR, within laminae III-V neurons, in the molecular mechanisms underlying morphine-induced hypersensitivity and raise the possibility that morphine selectively regulates the activity of certain populations of laminae III-V neurons.

The increased sensitivity of laminae III-V neurons to naspm and IEM-1460 observed using whole-cell patchclamp suggests insertion of GluA2-lacking AMPAR subunits at the synapse following morphine treatment. In addition, we also observed that morphine administration led to an increased rectification in the current-voltage relationships of AMPAR-mediated EPSCs further confirming that repeated morphine administration promotes the insertion of $\mathrm{Ca}^{2+}$-permeable AMPAR in laminae III-V neurons of the spinal cord. Our biochemical data suggests that these morphine-induced alterations in AMPAR-mediated EPCSCs are mainly due to changes in GluA4-containing AMPARs. Given the lack of a specific GluA4 blocker, we tested the role of GluA4 on morphine-induced neuroplasticity in the spinal cord by the intracellular application of GluA4 antibody through patch pipette. We observed that blockade of GluA4containing AMPAR in lamina III-V neurons of spinal cord totally reverses the observed morphine-induced alterations in current-voltage relationships of AMPA-mediated EPSCs. Similarly, intracellular infusion of GluA4 antibody reverses morphine-induced sensitivity to naspm. This is the first direct evidence for a role of GluA4-containing AMPAR in the mechanisms underlying morphine-induced pain sensitivity.

We propose that discontinuation of morphine treatment induces pain sensitivity through the synaptic insertion of GluA4-containing $\mathrm{Ca}^{2+}$-permeable AMPAR at spinal cord dorsal horn neurons. Therefore, this study highlights spinal GluA4-containing AMPAR as new targets to prevent the pain sensitivity that develops after the discontinuation of opioid treatment. 


\section{ACKNOWLEDGEMENTS}

This work was supported by NIH grants DA027460 (J.A.M., S.M.C) and DA025036 (J.A.M). We thank Dr Leonardo Pignataro for the generous gift of Synaptophysin-I antibody, Drs Amy B MacDermott and Chi-Kun Tong for the help with the spinal cord slice preparation technique, and Dr Jie Liu for sharing his laboratory equipment and technical expertise.

\section{DISCLOSURE}

The authors declare no conflict of interest.

\section{REFERENCES}

Angst MS, Clark JD (2006). Opioid-induced hyperalgesia: a qualitative systematic review. Anesthesiology 104: 570-587.

Atianjoh FE, Yaster M, Zhao X, Takamiya K, Xia J, Gauda EB et al (2010). Spinal cord protein interacting with C kinase 1 is required for the maintenance of complete Freund's adjuvantinduced inflammatory pain but not for incision-induced postoperative pain. Pain 151: 226-234.

Billa SK, Liu J, Bjorklund NL, Sinha N, Fu Y, Shinnick-Gallagher P et al (2010). Increased insertion of glutamate receptor 2-lacking alpha-amino-3-hydroxy-5-methyl-4-isoxazole propionic acid (AMPA) receptors at hippocampal synapses upon repeated morphine administration. Mol Pharmacol 77: 874-883.

Boehm J, Malinow R (2005). AMPA receptor phosphorylation during synaptic plasticity. Biochem Soc Trans 33: 1354-1356.

Buldakova SL, Kim KK, Tikhonov DB, Magazanik LG (2007). Selective blockade of $\mathrm{Ca} 2+$ permeable AMPA receptors in CA1 area of rat hippocampus. Neuroscience 144: 88-99.

Cabañero D, Campillo A, Célérier E, Romero A, Puig MM (2009). Pronociceptive effects of remifentanil in a mouse model of postsurgical pain: effect of a second surgery. Anesthesiology 111: 1334-1345.

Carlton SM, Du J, Tan HY, Nesic O, Hargett GL, Bopp AC et al (2009). Peripheral and central sensitization in remote spinal cord regions contribute to central neuropathic pain after spinal cord injury. Pain 147: 265-276.

Célérier E, Simonnet G, Maldonado R (2004). Prevention of fentanyl-induced delayed pronociceptive effects in mice lacking the protein kinase Cgamma gene. Neuropharmacology 46: 264-272.

Chakrabarti S, Regec A, Gintzler AR (2005). Chronic morphine acts via a protein kinase Cgamma-G(beta)-adenylyl cyclase complex to augment phosphorylation of G(beta) and G(betagamma) stimulatory adenylyl cyclase signaling. Brain Res Mol Brain Res 138: 94-103.

Chaplan SR, Bach FW, Pogrel JW, Chung JM, Yaksh TL (1994). Quantitative assessment of tactile allodynia in the rat paw. J Neurosci Methods 53: 55-63.

Chu LF, Clark DJ, Angst MS (2006). Opioid tolerance and hyperalgesia in chronic pain patients after one month of oral morphine therapy: a preliminary prospective study. J Pain 7: 43-48.

Crofford LJ (2010). Adverse effects of chronic opioid therapy for chronic musculoskeletal pain. Nat Rev Rheumatol 6: 191-197.

Drdla R, Gassner M, Gingl E, Sandkuhler J (2009). Induction of synaptic long-term potentiation after opioid withdrawal. Science 325: 207-210.

Esteban JA, Shi SH, Wilson C, Nuriya M, Huganir RL, Malinow R (2003). PKA phosphorylation of AMPA receptor subunits controls synaptic trafficking underlying plasticity. Nat Neurosci 6: 136-143.
Gangadharan V, Wang R, Ulzhofer B, Luo C, Bardoni R, Bali KK et al (2011). Peripheral calcium-permeable AMPA receptors regulate chronic inflammatory pain in mice. J Clin Invest 121: 1608-1623.

Gendron L, Esdaile MJ, Mennicken F, Pan H, O’Donnell D, Vincent JP et al (2007). Morphine priming in rats with chronic inflammation reveals a dichotomy between antihyperalgesic and antinociceptive properties of deltorphin. Neuroscience 144: 263-274.

Gomes AR, Correia SS, Esteban JA, Duarte CB, Carvalho AL (2007). PKC anchoring to GluR4 AMPA receptor subunit modulates PKC-driven receptor phosphorylation and surface expression. Traffic 8: 259-269.

Hay JL, White JM, Bochner F, Somogyi AA, Semple TJ, Rounsefell B (2009). Hyperalgesia in opioid-managed chronic pain and opioid-dependent patients. J Pain 10: 316-322.

Kopach O, Kao SC, Petralia RS, Belan P, Tao YX, Voitenko N (2011). Inflammation alters trafficking of extrasynaptic AMPA receptors in tonically firing lamina II neurons of the rat spinal dorsal horn. Pain 152: 912-923.

Latremoliere A, Woolf CJ (2009). Central sensitization: a generator of pain hypersensitivity by central neural plasticity. J Pain 10: 895-926.

Le Bars D, Gozariu M, Cadden SW (2001). Animal models of nociception. Pharmacol Rev 53: 597-652.

Liang D, Shi X, Qiao Y, Angst MS, Yeomans DC, Clark JD (2008). Chronic morphine administration enhances nociceptive sensitivity and local cytokine production after incision. Mol Pain 4: 7.

Liang DY, Li X, Clark JD (2011). 5-Hydroxytryptamine Type 3 Receptor Modulates Opioid-induced Hyperalgesia and Tolerance in Mice. Anesthesiology 114: 1180-1189.

Malinow R, Malenka RC (2002). AMPA receptor trafficking and synaptic plasticity. Annu Rev Neurosci 25: 103-126.

Man HY, Sekine-Aizawa Y, Huganir RL (2007). Regulation of \{alpha\}-amino-3-hydroxy-5-methyl-4-isoxazolepropionic acid receptor trafficking through PKA phosphorylation of the Glu receptor 1 subunit. Proc Natl Acad Sci USA 104: 3579-3584.

Moron JA, Abul-Husn NS, Rozenfeld R, Dolios G, Wang R, Devi LA (2007). Morphine administration alters the profile of hippocampal postsynaptic density-associated proteins: a proteomics study focusing on endocytic proteins. Mol Cell Proteomics 6: $29-42$.

Muscoli C, Doyle T, Dagostino C, Bryant L, Chen Z, Watkins LR et al (2010). Counter-regulation of opioid analgesia by glialderived bioactive sphingolipids. J Neurosci 30: 15400-15408.

Nagy GG, Al-Ayyan M, Andrew D, Fukaya M, Watanabe M, Todd AJ (2004). Widespread expression of the AMPA receptor GluR2 subunit at glutamatergic synapses in the rat spinal cord and phosphorylation of GluR1 in response to noxious stimulation revealed with an antigen-unmasking method. J Neurosci 24: 5766-5777.

Narita M, Mizoguchi H, Nagase H, Suzuki T, Tseng LF (2001). Involvement of spinal protein kinase Cgamma in the attenuation of opioid mu-receptor-mediated G-protein activation after chronic intrathecal administration of [D-Ala2,N-MePhe4, Gly-Ol(5)]enkephalin. J Neurosci 21: 3715-3720.

Okabe S, Miwa A, Okado H (2001). Spine formation and correlated assembly of presynaptic and postsynaptic molecules. J Neurosci 21: 6105-6114.

Park JS, Voitenko N, Petralia RS, Guan X, Xu JT, Steinberg JP et al (2009). Persistent inflammation induces GluR2 internalization via NMDA receptor-triggered PKC activation in dorsal horn neurons. J Neurosci 29: 3206-3219.

Polgar E, Al-Khater KM, Shehab S, Watanabe M, Todd AJ (2008a). Large projection neurons in lamina I of the rat spinal cord that lack the neurokinin 1 receptor are densely innervated by 
VGLUT2-containing axons and possess GluR4-containing AMPA receptors. J Neurosci 28: 13150-13160.

Polgar E, Watanabe M, Hartmann B, Grant SG, Todd AJ (2008b). Expression of AMPA receptor subunits at synapses in laminae I-III of the rodent spinal dorsal horn. Mol Pain 4: 5.

Polgar E, Wright LL, Todd AJ (2010). A quantitative study of brainstem projections from lamina I neurons in the cervical and lumbar enlargement of the rat. Brain Res 1308: 58-67.

Todd AJ, Polgar E, Watt C, Bailey ME, Watanabe M (2009). Neurokinin 1 receptor-expressing projection neurons in laminae III and IV of the rat spinal cord have synaptic AMPA receptors that contain GluR2, GluR3 and GluR4 subunits. Eur J Neurosci 29: 718-726.

Tong CK, MacDermott AB (2006). Both Ca2 + -permeable and impermeable AMPA receptors contribute to primary synaptic drive onto rat dorsal horn neurons. J Physiol 575: 133-144.

Tumati S, Roeske WR, Largent-Milnes TM, Vanderah TW, Varga EV (2011). Intrathecal PKA-selective siRNA treatment blocks sustained morphine-mediated pain sensitization and antinociceptive tolerance in rats. J Neurosci Methods 199: 62-68.

Vera-Portocarrero LP, Zhang ET, King T, Ossipov MH, Vanderah TW, Lai J et al (2007). Spinal NK-1 receptor expressing neurons mediate opioid-induced hyperalgesia and antinociceptive tolerance via activation of descending pathways. Pain 129: 35-45.

Xia Y, Portugal GS, Fakira AK, Melyan Z, Neve R, Lee HT et al (2011). Hippocampal GluA1-containing AMPA receptors mediate context-dependent sensitization to morphine. J Neurosci 31: 16279-16291.

Youn DH, Royle G, Kolaj M, Vissel B, Randic M (2008). Enhanced LTP of primary afferent neurotransmission in AMPA receptor GluR2-deficient mice. Pain 136: 158-167.

Zheng Z, Keifer J (2008). Protein kinase C-dependent and independent signaling pathways regulate synaptic GluR1 and GluR4 AMPAR subunits during in vitro classical conditioning. Neuroscience 156: 872-884.

Zimmermann M (1983). Ethical guidelines for investigations of experimental pain in conscious animals. Pain 16: 109-110. 